VIKTORS AJEVSKIS

KRISTĪNE VĪTOLA

\title{
A CONVERGENCE MODEL OF THE TERM STRUCTURE OF INTEREST RATES
}

WORKING PAPER

$1 \cdot 2009$

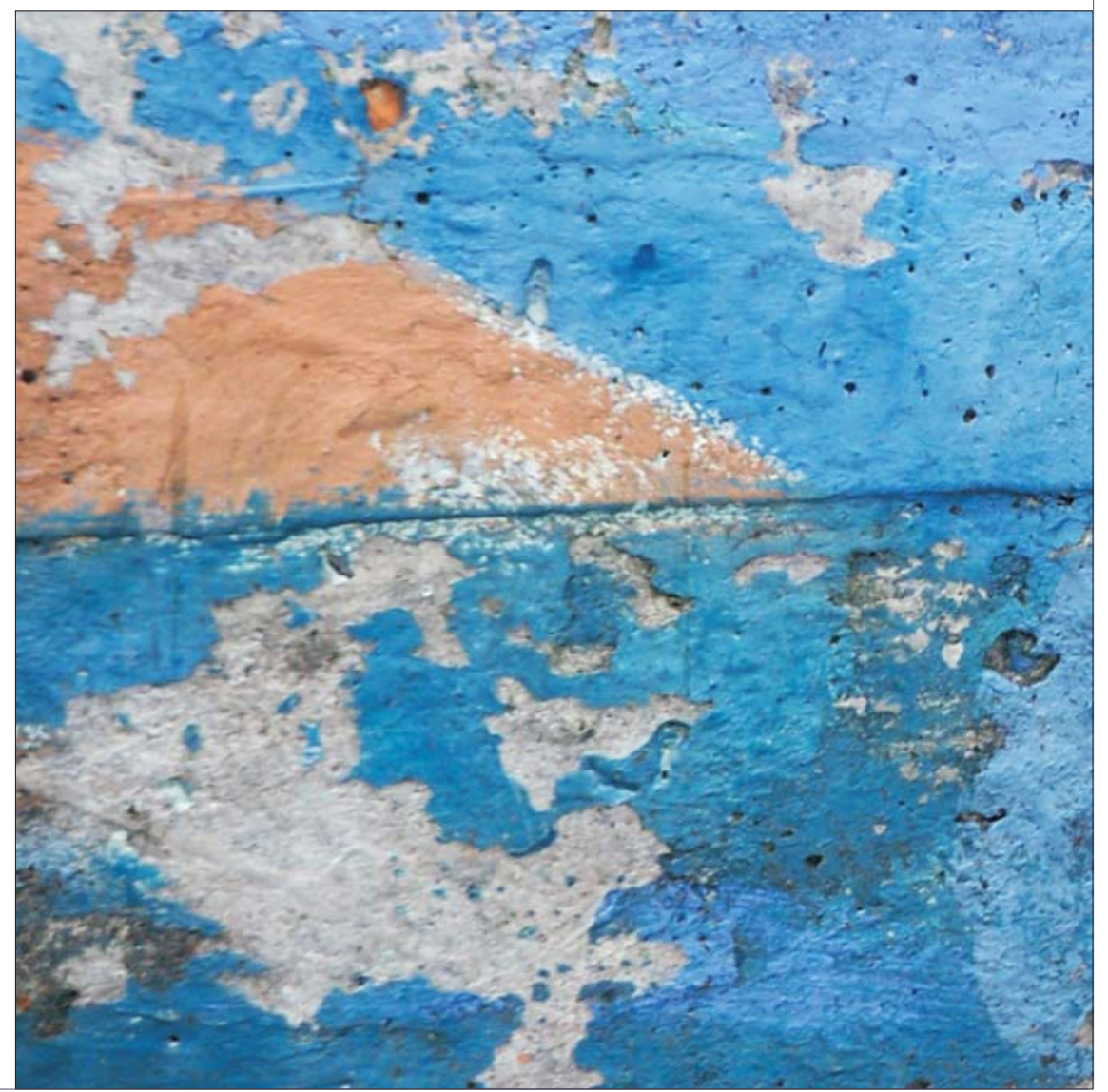




\section{CONTENTS}

Abstract 2

Introduction 3

1. Model Setup 5

1.1 Fixed Moment of Time for Country's Entry Into Euro Area 5

1.2 Random Moment of Time For Country's Accession to Euro Area 9

1.3 Implications of Model 11

2. Data 13

3. Estimations 13

4. Empirical Results 14

5. Conclusion 17

Appendices 18

1. Derivation of Discrete-Time State-Space Model Representation 18

2. Extended Kalman Filter Setup $\quad 22$

Bibliography $\quad 24$

BEF - Belgian frank

DEM - German mark

EMU - Economic and Monetary Union

ESP - Spanish peseta

EU - European Union

FIM - Finnish mark

FRF - French frank

ITL - Italian lira

NLG - Dutch gulden 
ABSTRACT

This paper develops a convergence model of the term structure of interest rates in the context of entering the EMU. Compared with the other models developed so far in this field, our model specification ensures convergence of the domestic short-term interest rates to the euro area ones. We achieve this convergence by stating that the spread between the domestic and euro short-term interest rates follows the Brownian bridge process. We also develop an econometric counterpart of the theoretical model. To address the problem of nonstationarity and nonlinearity of the model, the extended Kalman filter for coefficient estimation is applied.

Key words: term structure of interest rates, the Brownian bridge, the EMU, nonlinear Kalman filter.

JEL classification codes: E43, F36, G12, G15

The views expressed in this publication are those of the authors, employees of the Monetary Policy Department of the Bank of Latvia. The authors assume responsibility for any errors and omissions.

The authors would like to express their appreciation to Jesper Lund for providing the data. 


\section{INTRODUCTION}

In recent years, twelve countries have joined the EU. ${ }^{1}$ All new member states are required to join the EMU and adopt the euro as official currency. ${ }^{2}$ It is important for central banks in EMU candidate countries to develop financial asset pricing models, since on the basis of these models it would be possible to assess expectations of market participants with respect to various future events, for example, the expected entry date to the euro area or probability of joining the EMU by fixed date. For financial market participants these models would serve as an instrument to properly evaluate asset prices.

In international term structure models, the yield spread between different countries is determined by exchange rate risk. After joining the EMU, the yield spread between domestic and the euro area government bonds should disappear. ${ }^{3}$ Such event as country's accession to the euro area in the future certainly affects prices of financial assets. As long as any uncertainty with respect to this event exists, it will be reflected in the term structure of interest rates.

Jesper Lund in his work analyses the effect of planned EMU membership on domestic yield curves in potential member states.(13) The most interesting problems arise when there is some uncertainty about the member states of a monetary union or the initial possible entry date, or both; therefore, J. Lund pays the main attention to this case.

J. Lund develops an international term structure model which includes EMU entry plans, proposes a particular estimation method, and makes empirical conclusions. In his model, country's EMU accession date is a random variable. In the empirical analysis using interest rate data, J. Lund applies this feature to estimate the market implied probability of joining the EMU for each EU member state. Paul de Grauwe (4) and Carlo Ambrogio Favero et al. (7) consider similar ideas. David S. Bates (3) makes a review of literature and presents a detailed comparison of different methods for the EMU entry probability estimation.

In order to describe the dynamics of short-term spread (between domestic and euro interest rates) under the real probability measure, J. Lund applies the standard Vasicek process (Ornstein-Uhlenbeck) while extending the risk-neutral process with a second factor, i.e. the stochastic price of risk which also follows the Vasicek process.

It is not difficult to prove that in order to avoid an arbitrage opportunity the shortterm spread should converge to zero by the time of entering the currency area. J. Lund's specification does not ensure the fulfilment of this condition. In the present paper, we develop a term structure model of interest rates for a country that will join the euro area in the future. We define the specification of the short-term interest rate

1 In May 2004, Cyprus, the Czech Republic, Estonia, Hungary, Latvia, Lithuania, Malta, Poland, Slovakia, and Slovenia joined the EU. Bulgaria and Romania joined the EU in January 2007.

2 Slovenia adopted the euro in January 2007, Cyprus and Malta - in January 2008. Slovakia adopted the euro in January 2009.

${ }^{3}$ It is assumed that differences in such factors as liquidity, taxes, and credit risk do not exist. 
spread dynamics by the Brownian bridge process $(14 ; 15)$. This stochastic process has a property to converge to zero at a specific time moment. Therefore, the specification ensures convergence of the short-term spread to zero by country's entry into the euro area and thus avoids an arbitrage opportunity at this moment in time.

In order to model uncertainty of the EMU entrance date, we follow J. Lund (13) and use exponential distribution. The model structure is also related to works devoted to the modelling of credit risk dynamics $(16 ; 11)$.

We also develop an econometric counterpart of the theoretical model. To this end, we transform the continuous-time system into a discrete-time one. To address the problem of nonstationarity and nonlinearity of the model, we apply the extended Kalman filter for coefficient estimation.

The empirical results evidence that the developed model fits data better than Lund's single-factor model for Belgium, France, Italy, and Spain; it is the same for the Netherlands, and slightly worse for Finland. In addition, our model contains a smaller number of parameters than the rival one (4 against 5 ).

Subsection 1.1 of Section 1 provides theoretical grounds of arbitrage-free pricing, and on this basis we develop the term structure convergence model under the condition that the date of country's entry into the euro area is certainly known. Subsection 1.2 introduces the model extension under the condition that the euro area entry date is uncertain and derives formulas for the computation of the model term structure. Subsection 1.3 focuses on the implications of the model. Section 2 describes the data, Section 3 presents econometric methods for coefficient estimation of the developed model, and Section 4 contains empirical results. The last section concludes. 


\section{MODEL SETUP}

\subsection{Fixed Moment of Time for Country's Entry into Euro Area}

We consider two currencies - the euro and domestic currency. We denote the euro interest rate at time $t$ by $R(t)$ and the domestic one by $r(t)$. Thus, the short-term rate in the respective country satisfies

$r(t)=R(t)+\delta(t)$

where $\delta(t)$ is the local spread relative to $R(t)$. It is assumed that $R(t)$ and $\delta(t)$ are driven by independent stochastic processes. The following stochastic differential equations describe the dynamics of the local spread and euro short-term interest rate under the true probability measure:

$$
\begin{aligned}
& d \delta(t)=f_{1}(\delta, t) d t+\sigma_{1}(\delta) d w_{1}(t) \\
& d R(t)=f_{2}(R, t) d t+\sigma_{2}(R) d w_{2}(t)
\end{aligned}
$$

where $w_{1}(t)$ and $w_{2}(t)$ are two uncorrelated standard Brownian motion processes, $f_{1}$ and $f_{2}$ are drift coefficients for each process, whereas $\sigma_{1}(\delta)$ and $\sigma_{2}(R)$ are diffusion terms.(14) There are two market prices of risk, $\lambda_{1}, \lambda_{2}$, each corresponding to the source of uncertainty, $w_{1}(t)$ and $w_{2}(t)$ respectively.

Now a claim with a payoff in currency $i$ at time $T$, given by the function $h_{i}(T)$, is considered. Under the no-arbitrage principle, its price at time $t$ in units of currency $i$, obeys the following expression:

$E_{t}^{Q_{i}}\left[e^{-\int_{t}^{T} r_{i}(s) d s} h_{i}(T)\right], r_{i}=r$ or $R$

where $Q_{i}$ is the risk-neutral probability measure for currency $i$, and $E_{t}^{Q}$ is the conditional expectation operator under the probability measure $Q .(5)$

For the price at time $t$ of currency $i$ zero-coupon bond maturing at time $T$ in units of currency $i$, we have

$E_{t}^{Q_{i}}\left[e^{-\int_{t}^{T} r_{i}(s) d s} \cdot 1\right]$

Since it is obvious that after the entry into the euro area the term structures of domestic market and euro area interest rates will be the same, shortly before the euro area accession date the domestic zero-coupon bond prices denominated in domestic currency must almost coincide with the euro area zero-coupon bond prices denominated in euro. Besides, this fact is independent of the exchange rate level at the moment of the euro area entry. 
Let $P_{E}\left(T^{*}, T\right)$ be the time $T^{*}$ price of a euro bond maturing at time $T$. From equation [4] we get that the current (time $t$ ) domestic bond price for a given EMU membership date $T^{*}$, denoted by $P(t, T, T)$, is equal to

$P\left(t, T, T^{*}\right)=E_{t}^{Q}\left[e^{-\int_{t}^{T^{*}(R(s)+\delta(s)) d s}} P_{E}\left(T^{*}, T\right)\right]$

where the expectation is taken under $Q$, the risk-neutral probability measure for domestic currency. From equation [5] we obtain the time $T^{*}$ price of a euro bond maturing at time $T$

$P_{E}\left(T^{*}, T\right)=E_{T^{*}}^{Q_{E}}\left[e^{-\int_{T^{*}}^{T} R(s) d s}\right]=E_{T^{*}}^{Q}\left[e^{-\int_{T^{*}}^{T} R(s) d s}\right]$

It is taken into account that after the euro area entry time measures $Q$ and $Q_{E}$ must coincide.

The Radon-Nikodym derivative defines the relationship between two probability measures.(5) Assuming that the Radon-Nikodym derivative is independent of $R_{t}$, we can write the price of a euro bond as

$P_{E}(t, T)=\mathrm{E}_{\mathrm{t}}^{\mathrm{Q}_{\mathrm{E}}}\left[e^{-\int_{t}^{T} R(s) d s}\right]=\frac{\mathrm{E}_{\mathrm{t}}^{\mathrm{Q}}\left[\frac{d \mathrm{Q}_{\mathrm{E}}}{d Q} e^{-\int_{t}^{T} R(s) d s}\right]}{\mathrm{E}_{\mathrm{t}}^{\mathrm{Q}}\left[\frac{d \mathrm{Q}_{\mathrm{E}}}{d Q}\right]}=\frac{\mathrm{E}_{\mathrm{t}}^{\mathrm{Q}}\left[\frac{d \mathrm{Q}_{\mathrm{E}}}{d Q}\right] \mathrm{E}_{\mathrm{t}}^{\mathrm{Q}}\left[e^{-\int_{t}^{T} R(s) d s}\right]}{\mathrm{E}_{\mathrm{t}}^{\mathrm{Q}}\left[\frac{d \mathrm{Q}_{\mathrm{E}}}{d Q}\right]}=\mathrm{E}_{\mathrm{t}}^{\mathrm{Q}}\left[e^{-\int_{t}^{T} R(s) d s}\right]$

[8].

Thus, it follows that we can obtain the euro bond price by taking expectations under either the domestic risk-neutral probability measure $Q$ or euro measure $Q_{E}$.

Substituting equation [7] into equation [6] and using the law of iterated expectations, we obtain

$$
\begin{aligned}
& P\left(t, T, T^{*}\right)=E_{t}^{Q}\left[e^{-\int_{t}^{T^{*}}(R(s)+\delta(s) d s} E_{T^{*}}^{Q}\left(e^{-\int_{T^{*}}^{T} R(s) d s}\right]=E_{t}^{Q}\left[E_{T^{*}}^{Q}\left(e^{-\iint_{t}^{T}(R(s)+\delta(s) d s} \cdot e^{-\int_{T^{*}}^{T} R(s) d s}\right)\right]=\right. \\
& =E_{t}^{Q}\left[e^{-\int_{t}^{T} R(s) d s} \cdot e^{-\int_{t}^{T^{*} \delta(s) d s}}\right]=E_{t}^{Q}\left[e^{-\int_{t}^{T} R(s) d s}\right] \cdot E_{t}^{Q}\left[e^{\left.-\int_{t}^{T^{*} \delta(s) d s}\right]}\right]=P_{E}(t, T) \cdot D\left(t, T^{*}\right)
\end{aligned}
$$

where 
$D\left(t, T^{*}\right)=E_{t, \delta}^{Q}\left[e^{-\iint_{t}^{*} \delta(s) d s}\right]$

is the local discount factor relating the domestic and euro bond prices. If the time to maturity $T<T^{*}$, formula [10] can be rewritten as

$D(t, T)=\mathrm{E}_{\mathrm{t}, \delta}^{\mathrm{Q}}\left[e^{-\int_{t}^{T} \delta(s) d s}\right]$

The subscripts $t$ and $\delta$ denote that the expectation shall be taken, given the following dynamics of the factor:

$d \delta(s)=\left(f_{1}(\delta(s), s)-\sigma_{1}(\delta(s)) \lambda_{1}(\delta(s), s)\right) d s+\sigma_{1}(\delta(s)) d \tilde{w}(s)$

$\delta=\delta(t)$

where $\widetilde{w}$ is a Wiener process under measure $Q$.

Formula [11] is the Feynman-Kac representation of the solution of the following parabolic partial differential equation:

$D_{t}(\delta, t)+\left(f_{1}(\delta, t)-\sigma_{1}(\delta) \lambda_{1}(\delta, t)\right) D_{\delta}(\delta, t)+\frac{1}{2} D_{\delta \delta}(\delta, t) \sigma_{1}^{2}(\delta)-\delta D(\delta, t)=0$

with the terminal condition

$D(\delta, T)=1$.

It is further assumed that the drift term in equation [2] has the following form:

$f_{1}(\delta, t)=-\frac{\delta}{T^{*}-t}$

and $\sigma_{1}(\delta)=\sigma=$ const. This implies the following stochastic differential equation under the true measure $P$ :

$d \delta(t)=-\frac{\delta(t)}{T^{*}-t} d t+\sigma d w_{1}(t)$

It is assumed that $T^{*}$ is the time of entry into the euro area. The process defined in [17] is well known in the stochastic process theory as the so-called Brownian bridge. $(14 ; 15)$ The property of this process is that it is equal to zero at time $T^{*}$ with probability 1 . The purpose of this specification is to ensure convergence of the spread to zero by the date of entering the euro area, which guarantees equal domestic and euro interest rates. As the true measure $P$ and risk-neutral measure $Q$ are equivalent, the events with probability 1 under measure $P$ will also have probability 
1 under measure $Q$. Therefore, probability of event $\left\{\delta\left(T^{*}\right)=0\right\}$ will be equal to 1 also under the risk-neutral measure $Q .{ }^{4}$

The motivation to choose such specification is that if the spread was non-zero at the moment of entry, arbitrage would be possible. The exchange rate alone would be insufficient to accommodate the non-zero spread because at this time the former would be fixed to some level known in advance. It is not possible to guarantee a zero short-term rate spread just before joining the euro area using the conventional model specifications (Vasicek, Cox-Ingersoll-Ross, multi-factor affine, etc).

Substituting equation [16] into equation [14], we get

$$
D_{t}-\left(\frac{\delta}{T^{*}-t}+\sigma_{1} \lambda_{1}(\delta, t)\right) D_{\delta}+\frac{1}{2} D_{\delta \delta} \sigma_{1}^{2}-\delta D=0
$$

We also allow the price of risk $\lambda_{1}$ to be constant. Let us consider now the case of the affine term structure model

$$
D(\delta, \tau)=\exp [\mathrm{A}(\tau)-\delta B(\tau)]
$$

where $\tau=T-t \geq 0$.

Then the various partial derivatives of $D(\delta, \tau)$ are

$$
\begin{aligned}
& D_{t}=\left(-A^{\prime}(\tau)+B^{\prime}(\tau) \delta\right) e^{\mathrm{A}(\tau)-\delta B(\tau)}=\left(-A^{\prime}(\tau)+B^{\prime}(\tau) \delta\right) D(\tau) \\
& D_{\delta}=-B(\tau) e^{\mathrm{A}(\tau)-\delta B(\tau)}=-B(\tau) D(\tau) \\
& D_{\delta \delta}=B^{2}(\tau) e^{\mathrm{A}(\tau)-\delta B(\tau)}=B^{2}(\tau) D(\tau)
\end{aligned}
$$

Inserting equations [20] and [21] into partial differential equation [18] gives the following expression:

$$
\left(-A^{\prime}(\tau)+B^{\prime}(\tau) \delta\right) D(\tau)+\left(\frac{\delta}{T^{*}-t}+\sigma_{1} \lambda_{1}\right) B(\tau) D(\tau)+\frac{1}{2} \sigma_{1}^{2} B^{2}(\tau) D(\tau)-\delta D(\tau)=0
$$

The cancelling of $D$, taking into account that $t=T-\tau$, and rearranging of the terms give

$$
\left[-A^{\prime}(\tau)+\frac{1}{2} \sigma_{1}^{2} B^{2}(\tau)+\sigma_{1} \lambda_{1} B(\tau)\right]+\left[B^{\prime}(\tau)+\frac{1}{T^{*}-T+\tau} B(\tau)-1\right] \delta=0 .
$$

${ }^{4}$ Under the risk-neutral measure the short-term spread process is $d \delta(t)=\left[-\frac{\delta(t)}{T^{*}-t}-\lambda \sigma\right] d t+\sigma d \tilde{w}(t)$. It is not difficult to show that this process has the following representation (if $\lambda$ is constant): $\delta(t)=\left(T^{*}-t\right) \int_{0}^{t} \frac{1}{T^{*}-u} d w(u)+\frac{\delta(0)\left(T^{*}-t\right)}{T^{*}}-\sigma \lambda\left(T^{*}-t\right) \ln \left(\frac{T^{*}-t}{T^{*}}\right)$, where the first and second terms represent the standard Brownian bridge process from $\delta(0)$ to 0 , and the third term is deterministic function with 0 terminal value at $T^{*}$. 
The last equation holds for all $\delta$ and $\tau$ values, and we can conclude that the two terms in brackets are equal to zero. This reduces the problem to solving the following system of two ordinary differential equations:

$-A^{\prime}(\tau)+\frac{1}{2} \sigma_{1}^{2} B^{2}(\tau)+\sigma_{1} \lambda_{1} B(\tau)=0$

$B^{\prime}(\tau)+\frac{1}{T^{*}-T+\tau} B(\tau)=1$

Solving the system of equations [23] and [24] under initial conditions that $A(0)=0$ and $B(0)=0$ gives the solution of affine term structure model [19]

$$
\begin{aligned}
& B(t, T)=\frac{1}{2}\left[T^{*}-t-\frac{\left(T^{*}-T\right)^{2}}{\left(T^{*}-t\right)}\right] \\
& A(t, T)=\frac{\sigma_{1}^{2}}{8}\left[\frac{\left(T^{*}-t\right)^{3}}{3}-2\left(T^{*}-T\right)^{2}(T-t)-\frac{\left(T^{*}-T\right)^{4}}{\left(T^{*}-t\right)}+\frac{2}{3}\left(T^{*}-T\right)^{3}\right]+ \\
& +\frac{1}{2} \lambda \sigma\left[\frac{\left(T^{*}-t\right)^{2}}{2}-\frac{\left(T^{*}-T\right)^{2}}{2}-\left(T^{*}-T\right)^{2} \ln \left(\frac{\left(T^{*}-t\right)}{\left(T^{*}-T\right)}\right)\right]
\end{aligned}
$$

\subsection{Random Moment of Time for Country's Accession to Euro Area}

The decision on a country's accession to the euro area and its date is made by the EU institutions. Prior to it, there is uncertainty of some degree with respect to the moment of time $T^{*}$. To accomplish the model, it is necessary to define probability distribution of $T^{*}$ at time $t$ (under the risk-neutral measure). The probability that a country will not join the euro area prior to time $u$ is defined in the following form:

$\operatorname{Pr}(t)\left\{T^{*}>u\right\}=\exp \left(-\int_{t}^{u} \pi(s) d s\right), \pi(s) \geq 0$

The probability density function is the derivative of distribution function with respect to $u$

$$
p(t, u)=\frac{d}{d u} \operatorname{Pr}(t)\left\{T^{*} \leq u\right\}=\frac{d}{d u}\left[1-\operatorname{Pr}(t)\left\{T^{*}>u\right\}\right]=\pi(u) \exp \left(-\int_{t}^{u} \pi(s) d s\right)
$$

where $\pi(s)$ is a hazard function.

Given the distribution of $T^{*}$, by computing the expected value of equation [9] for all possible euro area accession dates $T^{*}$, we can obtain the bond price 


$$
\begin{aligned}
& P(t, T)=\int_{t}^{\infty} P\left(t, T, T^{*}\right) p\left(t, T^{*}\right) d T^{*}=\int_{t}^{\infty} P_{E}(t, T) D\left(t, T, T^{*}\right) p\left(t, T^{*}\right) d T^{*}= \\
& =P_{E}(t, T)\left[\int_{t}^{\infty} D\left(t, T, T^{*}\right) p\left(t, T^{*}\right) d T^{*}\right]
\end{aligned}
$$

where $D\left(t, T, T^{*}\right)=\exp \left[A\left(t, T, T^{*}\right)-\delta B_{1}\left(t, T, T^{*}\right)\right]$ (from equation [19]) but $A$ and $B_{1}$ follow from equations [25] and [26] respectively.

We define the hazard function in the following form (13):

$\pi(s)=\left\{\begin{array}{l}0, s<\tilde{T} \\ \theta, s \geq \tilde{T}\end{array}\right.$

where $\tilde{T}$ is the moment of time which corresponds to some certain time in the future, and the constant $\theta>0$. The specification of this model does not admit accession to the euro area before date $\widetilde{T}$.

The function $D\left(t, T, T^{*}\right)$ satisfies the following equation:

$$
D\left(t, T, T^{*}\right)=\left\{\begin{array}{l}
D\left(t, T, T^{*}\right), T<T^{*} \\
D\left(t, T^{*}, T^{*}\right), T>T^{*}
\end{array}\right.
$$

Thus, given this hazard function, we can rewrite the bond price from equation [29] as

$$
P(t, T)=\left\{\begin{array}{c}
P_{E}(t, T) \cdot \theta \int_{\widetilde{T}}^{\infty} D\left(t, T, T^{*}\right) e^{-\theta\left(T^{*}-\tilde{T}\right)} d T^{*}, T \leq \tilde{T} \\
P_{E}(t, T) \cdot \theta\left\{\int_{\widetilde{T}}^{T} D\left(t, T^{*}, T^{*}\right) e^{-\theta\left(T^{*}-\tilde{T}\right)} d T^{*}+\int_{T}^{\infty} D\left(t, T, T^{*}\right) e^{-\theta\left(T^{*}-\tilde{T}\right)} d T^{*}\right\}, T>\widetilde{T}
\end{array}\right.
$$

or

$$
P(t, T)=P_{E}(t, T) F(t, T)
$$

where

$$
F(t, T)=\left\{\begin{array}{c}
\theta \int_{\widetilde{T}}^{\infty} D\left(t, T, T^{*}\right) e^{-\theta\left(T^{*}-\widetilde{T}\right)} d T^{*}, T \leq \tilde{T} \\
\theta\left\{\int_{\widetilde{T}}^{T} D\left(t, T^{*}, T^{*}\right) e^{-\theta\left(T^{*}-\widetilde{T}\right)} d T^{*}+\int_{T}^{\infty} D\left(t, T, T^{*}\right) e^{-\theta\left(T^{*}-\widetilde{T}\right)} d T^{*}\right\}, T>\widetilde{T}
\end{array}\right.
$$

Taking into account equations [31] and [32], we can compute yield to maturity for zero-coupon bond: 


$$
\begin{aligned}
& y(t, T)=-\frac{\log P(t, T)}{T-t}=-\frac{\log \left(P_{E}(t, T) \cdot F(t, T)\right)}{T-t}=-\frac{\log P_{E}(t, T)}{T-t}-\frac{\log F(t, T)}{T-t}= \\
& =y_{E}(t, T)+S(t, T)=y_{E}(\tau)+S(\tau)
\end{aligned}
$$

where $y_{E}(\tau)$ is the yield to maturity for euro bonds with the term to maturity $\tau=T-t$, and $S(t, T)=S(\tau)$ is yield spread of the respective term to maturity.

\subsection{Implications of Model}

In Lund's model, yield spreads for rates with pre-entry date maturities can not be affected by the EMU accession, which, however, is not consistent with the data (see Charts 1-3). In the proposed model, the EMU affects all maturities, which, in our opinion, is more realistic.

To show that the proposed model gives a plausible outcome, we consider numerical examples. The first example deals with a country having a strong probability of joining the EMU. For this country, coefficient $\theta=4$, i.e. the probability of joining the EMU within 1 year from date $\widetilde{T}$ is equal to $p=1-e^{-\theta}=0.98$. The current value of state variable is $\delta=0.02$. For the second country, coefficient $\theta=0.01$, i.e. the probability of joining the EMU within 1 year from date $\widetilde{T}$ is equal to $p=1-e^{-\theta}=$ 0.01 , or is very low.

Chart 1

2-year interest rate spreads on transactions in BEF, FRF and NLG to DEM

(\%; weeks (14 August 1996-12 August 1998))

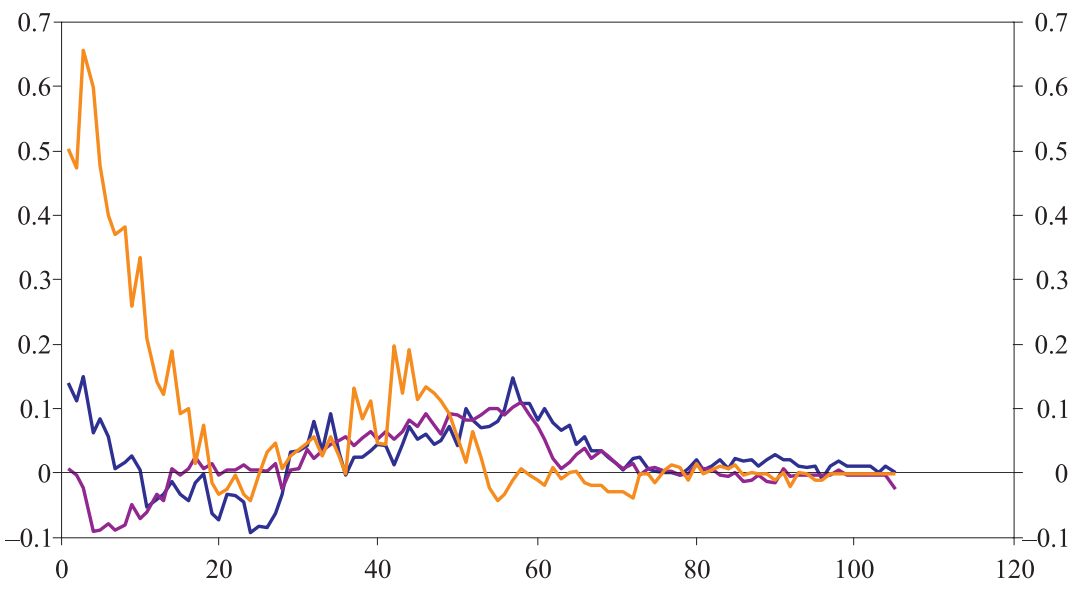


Chart 2

10-year interest rate spreads on transactions in BEF, FRF and NLG to DEM

(\%; weeks (14 August 1996-12 August 1998))

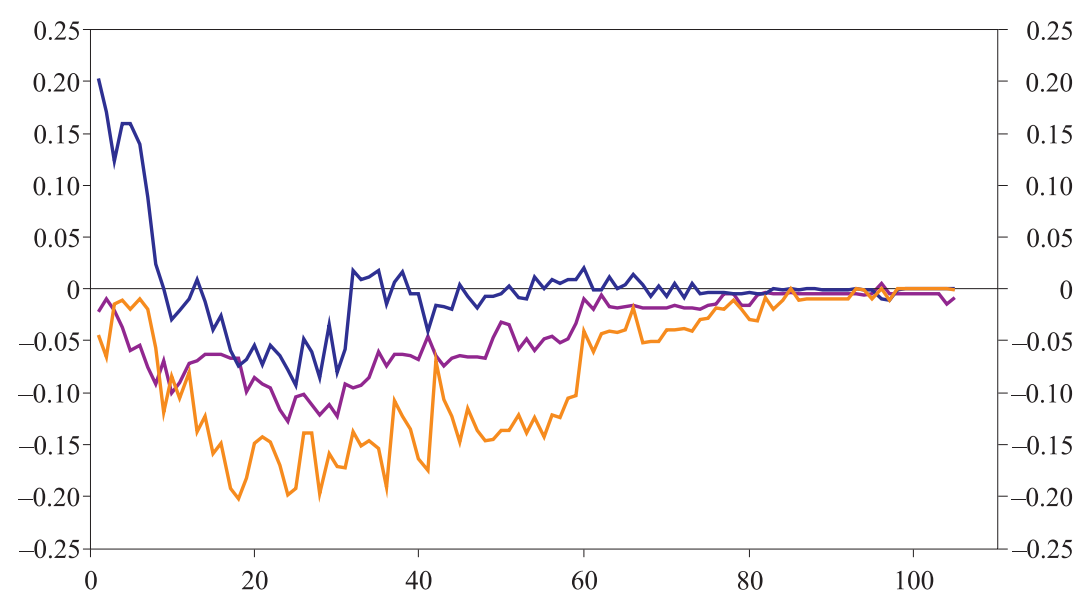

\section{Chart 3}

2- and 10-year interest rate spreads on transactions in ESP, FIM and ITL to DEM

(\%; weeks (14 August 1996-12 August 1998))
ESP (2-year spread)

FIM (2-year spread)

ITL (2-year spread)

- ESP (10-year spread)

— FIM (10-year spread)

- ITL (10-year spread)

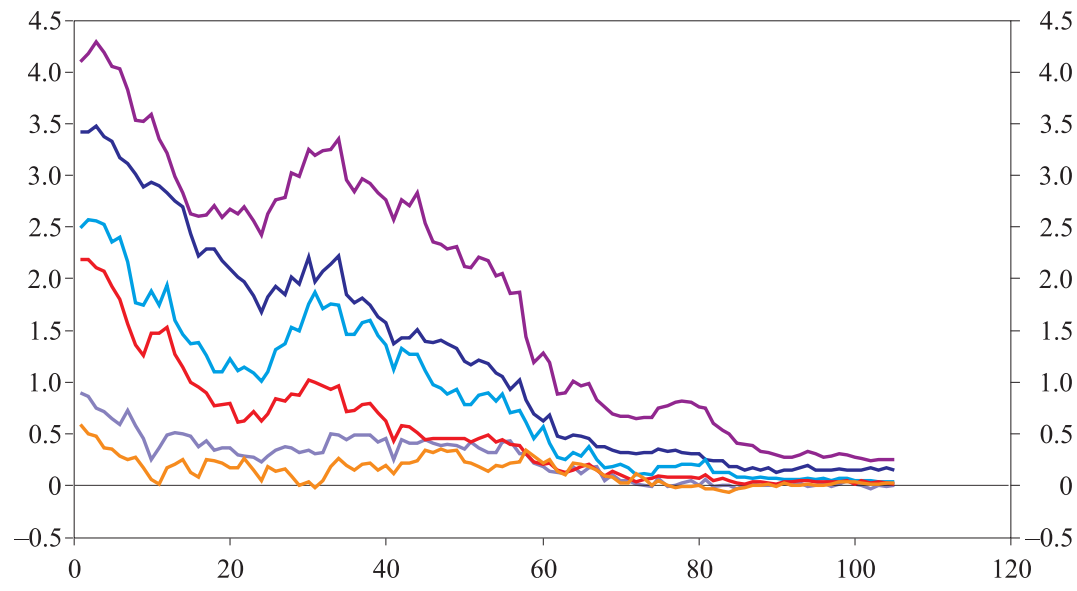

Chart 4 displays the term structure of the spread for both countries with the 3-year term $(u=\widetilde{T}-t=3)$ and 1 -year term to date $\widetilde{T}(u=\widetilde{T}-t=1)$. For the country with a high probability of joining the EMU, the term structure of interest rate spread is rapidly decreasing with maturity in both cases; however, the shorter the term to the possible EMU accession date, the more rapid the decrease. The short-term interest rate spread is about $2 \%$, whereas the 10 -year spread is 32 basis points for the 3 -year term and 12 basis points for 1-year term. For the low probability country, the term structure of interest rate spread is decreasing very gradually and is almost independent of term $\tilde{T}-t$. The 10 -year interest rate spread slightly exceeds $1.6 \%$. 


\section{Chart 4}

Theoretical term structure of interest rate spread

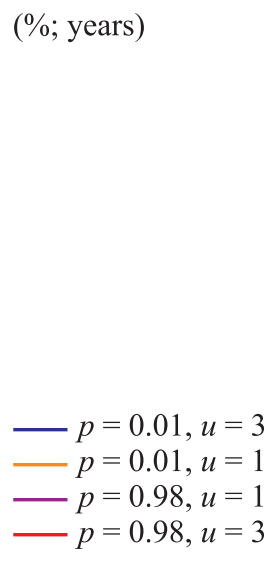

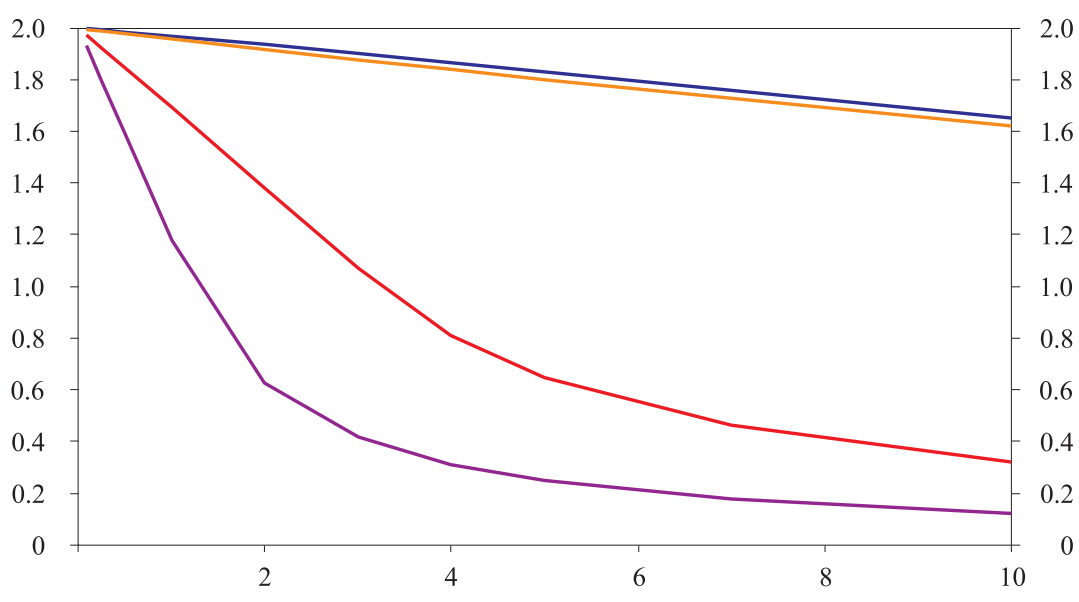

For the country with strong probability of joining the EMU $\theta=4$, i.e. the probability of joining the EMU within 1 year from date $\widetilde{T}$ is equal to $\mathrm{p}=1-e^{-\theta}=0.98$ and the current value of state variable is $\delta=0.02$. For the second country, coefficient $\theta=0.01$, i.e. the probability of joining the EMU within 1 year from date $\widetilde{T}$ is equal to $p=1-e^{-\theta}=0.01$, i.e. very low. $u=\widetilde{T}-t-$ term to the possible EMU accession date $\tilde{T}$.

\section{DATA}

For the estimation of model parameters following J. Lund's paper (13), we use money market and swap rates. The money market data include interest rates with maturities of 1, 3, 6 and 12 months, whereas the swap market data include rates with maturities of 2-5, 7, and 10 years. The following currencies were considered: BEF, FRF, FIM, ITL, ESP, and NLG. All data are spreads between the corresponding national currency and DEM yields. The yields are sampled weekly (Wednesdays) from 14 August 1996 to 12 August 1998. We choose such a sample due to pronounced observable convergence of yield spreads to zero in this period, with the data revealing properties of the Brownian bridge process (see Charts 1-3).

\section{ESTIMATIONS}

Let us assume that $n$ interest rates with maturities $\tau_{1}, \tau_{2}, \ldots, \tau_{n}$ exist in the market. The corresponding spreads with respect to euro interest rates are $\tilde{S}\left(\tau_{1}\right), \ldots, \tilde{S}\left(\tau_{n}\right)$. In this case, taking into account equation [17], the model developed above can be written as

$$
\begin{aligned}
& d \delta=-\frac{\delta}{T^{*}-t} d t+\sigma_{\delta} d w_{\delta} \\
& \tilde{S}\left(t, \tau_{i}\right)=S\left(t, \delta, \psi, \tau_{i}\right)+\eta_{i}(t), i=1,2, \ldots, n
\end{aligned}
$$


where $S\left(t, \delta, \psi, \tau_{i}\right)=-\frac{\log F\left(t, \delta, \psi, \tau_{i}\right)}{\tau_{i}}$ is the theoretical spread from equation [34] ( $S$ depends on $\delta$ since it follows from equation [19] that $D$ depends on $\delta$ ), $\eta_{i} \sim N\left(0, \sigma_{\eta}^{2} I\right)$ is the measurement errors, $\psi$ is the vector of model parameters, and $\psi=\left(\theta, \sigma_{\eta}, \sigma_{\delta}, \lambda_{1}\right)$.

The system of equations [35] and [36] determines a nonlinear continuous-time statespace system where equation [35] is a transition equation and equation [36] is a measurement equation. (8; 9)

In order to estimate the parameter vector $\psi$, we need to transform the system of equations [35] and [36] into a discrete-time form and use the extended Kalman filter (9) due to nonlinearity of measurement equations ${ }^{5}$ (see Appendix for details of this procedure).

\section{EMPIRICAL RESULTS}

The estimation results obtained with the proposed model are reported in the table. All parameters are statistically significant. Parameterisation of the hazard function in equation [35] means that the probability of joining the EMU within one year from January 1999 is equal to $1-\exp (-\theta)$. The estimation of parameter $\theta$ is to some extent consistent with J. Lund's estimation.(13) There was a strong probability of joining the EMU for Belgium and France. For Finland, Italy and Spain the probability was small. For the Netherlands parameter $\theta$ is equal to 0.86 , which means that the probability of joining the EMU within one year from January 1999 is equal to 0.58 . This probability appears to be too small. It can be explained by the fact that for the Netherlands the spread for short-term maturities did not converge to zero over the considered sample but only fluctuated around it (see Chart 1). Therefore, it is not possible to capture the dynamics of the observable short spread with the help of the Brownian bridge process.

\footnotetext{
${ }^{5}$ We can not apply GMM (Generalised Method of Moments) due to non-stationarity of the model.
} 
Table

Comparison of estimates of Brownian bridge model with Lund's single-factor model (13) with constant hazard function

(both models are for yield spreads to DEM)

\begin{tabular}{|c|c|c|c|c|c|c|}
\hline Currency & Model & $\theta$ & $\sigma_{\eta} \times 10^{-3}$ & $\sigma_{\delta} \times 10^{-3}$ & $\lambda$ & $k$ \\
\hline \multirow[t]{2}{*}{$\mathrm{BEF}$} & Brownian bridge & $\begin{array}{c}45.1 \\
(0.06)\end{array}$ & $\begin{array}{c}0.53 \\
(0.01)\end{array}$ & $\begin{array}{c}5.60 \\
(0.43)\end{array}$ & $\begin{array}{c}0.118 \\
(0.001)\end{array}$ & $\begin{array}{l}- \\
-\end{array}$ \\
\hline & Lund's model & $\begin{array}{l}266 \\
(0.3)\end{array}$ & $\begin{array}{c}0.63 \\
(0.02)\end{array}$ & $\begin{array}{c}3.62 \\
(0.40)\end{array}$ & $\begin{array}{l}-0.0006 \\
(0.0728)\end{array}$ & $\begin{array}{c}0.207 \\
(0.034)\end{array}$ \\
\hline \multirow[t]{2}{*}{ ESP } & Brownian bridge & $\begin{array}{c}0.148 \\
(0.001)\end{array}$ & $\begin{array}{c}1.49 \\
(0.03)\end{array}$ & $\begin{array}{c}5.39 \\
(0.10)\end{array}$ & $\begin{array}{c}0.920 \\
(0.002)\end{array}$ & - \\
\hline & Lund's model & $\begin{array}{c}0.599 \\
(0.061)\end{array}$ & $\begin{array}{c}1.98 \\
(0.04)\end{array}$ & $\begin{array}{c}5.74 \\
(0.54)\end{array}$ & $\begin{array}{c}0.0205 \\
(0.0216)\end{array}$ & $\begin{array}{c}0.939 \\
(0.118)\end{array}$ \\
\hline \multirow[t]{2}{*}{ FIM } & Brownian bridge & $\begin{array}{c}0.0810 \\
(0.0002)\end{array}$ & $\begin{array}{c}1.18 \\
(0.03)\end{array}$ & $\begin{array}{c}5.93 \\
(0.04)\end{array}$ & $\begin{array}{l}-0.306 \\
(0.002)\end{array}$ & $\begin{array}{l}- \\
-\end{array}$ \\
\hline & Lund's model & $\begin{array}{c}0.247 \\
(0.053)\end{array}$ & $\begin{array}{l}1.10 \\
(0.04)\end{array}$ & $\begin{array}{c}3.53 \\
(1.70)\end{array}$ & $\begin{array}{c}2.33 \times 10^{-6} \\
\left(2.07 \times 10^{-5}\right)\end{array}$ & $\begin{array}{l}-0.440 \\
(0.283)\end{array}$ \\
\hline \multirow[t]{2}{*}{ FRF } & Brownian bridge & $\begin{array}{c}3.93 \\
(0.118)\end{array}$ & $\begin{array}{c}0.74 \\
(0.02)\end{array}$ & $\begin{array}{c}4.12 \\
(0.51)\end{array}$ & $\begin{array}{l}-0.396 \\
(0.055)\end{array}$ & $\begin{array}{l}- \\
-\end{array}$ \\
\hline & Lund's model & $\begin{array}{c}268 \\
(41.1)\end{array}$ & $\begin{array}{c}0.75 \\
(0.03)\end{array}$ & $\begin{array}{c}3.50 \\
(0.22)\end{array}$ & $\begin{array}{r}1.38 \times 10^{-6} \\
\left(1.11 \times 10^{-5}\right)\end{array}$ & $\begin{array}{c}0.893 \\
(0.040)\end{array}$ \\
\hline \multirow[t]{2}{*}{ ITL } & Brownian bridge & $\begin{array}{c}0.159 \\
(0.001)\end{array}$ & $\begin{array}{c}2.56 \\
(0.06)\end{array}$ & $\begin{array}{c}7.74 \\
(0.16)\end{array}$ & $\begin{array}{c}1.034 \\
(0.001)\end{array}$ & $\begin{array}{l}- \\
-\end{array}$ \\
\hline & Lund's model & $\begin{array}{c}0.595 \\
(0.012)\end{array}$ & $\begin{array}{c}3.39 \\
(0.09)\end{array}$ & $\begin{array}{c}7.90 \\
(0.22)\end{array}$ & $\begin{array}{l}-1.50 \times 10^{-6} \\
\left(8.46 \times 10^{-6}\right)\end{array}$ & $\begin{array}{c}1.10 \\
(0.034)\end{array}$ \\
\hline \multirow[t]{2}{*}{ NLG } & Brownian bridge & $\begin{array}{c}0.857 \\
(0.084)\end{array}$ & $\begin{array}{c}0.58 \\
(0.01)\end{array}$ & $\begin{array}{c}3.88 \\
(0.43)\end{array}$ & $\begin{array}{c}-0.2418 \\
(0.034)\end{array}$ & $\begin{array}{l}- \\
-\end{array}$ \\
\hline & Lund's model & $\begin{array}{c}258 \\
(14.3)\end{array}$ & $\begin{array}{c}0.58 \\
(0.01)\end{array}$ & $\begin{array}{c}5.91 \\
(0.66)\end{array}$ & $\begin{array}{c}1.839 \\
(0.231)\end{array}$ & $\begin{array}{l}-0.132 \\
(0.028)\end{array}$ \\
\hline
\end{tabular}

The Brownian bridge model uses the extended Kalman filter for coefficient estimation (for details see Appendices). Lund's model is a single-factor model with constant hazard function (13)). The sample includes the period from August 1996 to August 1998. $\sigma_{\eta}$ is standard deviation of measurement error for observable yield spread to DEM, $\sigma_{\delta}$ is the instantaneous volatility of short-term spread, $\lambda$ is the price of risk, $k$ is the mean reversion parameter for Lund's model. The hazard function $\pi(s)$, is zero for $s<\tilde{T}$ and $\theta$ for $s \geq \tilde{T}$, where $\tilde{T}$ is the moment of time before which the model does not admit accession to the EMU. The probability that a country will not join the EMU before time $u$ is

$\operatorname{Pr}(t)\left\{T^{*}>u\right\}=\exp \left(-\int_{t}^{u} \pi(s) d s\right)$

$T^{*}$ stands for the date of joining the EMU.

Standard errors are in parenthesis.

In order to evaluate the in-sample fitting performance of the Brownian bridge model, we compare its standard deviation of the measurement error with the one in a singlefactor version of Lund's model (13) with the constant hazard function. In particular, under the real measure $P$, the dynamics of short-term yield spread is governed by the Vasicek process

$d \delta(t)=-k \delta(t) d t+\sigma_{\delta} d w_{1}(t)$

We use the extended Kalman filter to estimate five parameters of the single-factor version of Lund's model (13) with constant hazard function $k, \lambda, \sigma_{\delta}, \theta$ and $\sigma_{\eta}$, where 
$k$ is the mean reversion parameter, $\sigma_{\delta}$ is the instantaneous volatility of the short-term interest rate spread, $\lambda$ is the price of risk, and $\sigma_{\eta}$ is the standard deviation of measurement error. The estimation procedure is described in Appendix 2. In parameter estimation of the model, we use the same sample as for the Brownian bridge model.

The rationale to choose the specification of Vasicek model without unconditional mean lies in the property of the conditional expectation of the process $E_{t_{0}}(\delta(t))$ to converge to zero as time $t$ tends to infinity. This property can capture convergence in the historical time series.

The Table shows the estimation results for both models. The comparison of standard deviations of measurement errors for the two models shows that the proposed model gives a better in-sample fitting for almost all countries, except for the Netherlands and Finland. Moreover, it contains a smaller number of parameters than the rival one (4 against 5).

In the case of the Netherlands, the standard deviations of measurement error are equal for both models. This can be explained by the abovementioned incompletely correct specification of the Brownian bridge process for the short-term spread over the considered sample. For Finland, the Brownian bridge model gives a slightly greater standard deviation of measurement error, which can be accounted for by the observed diverging term structure of yield spreads (see Chart 3). The latter implies that an additional factor is needed to describe the behavior of Finnish yield spreads correctly.

It should be noted that in Lund's model the mean reversion coefficient $k$ has a negative sign for Finland and the Netherlands. It suggests that the model dynamics becomes unstable and thus lacks any economic sense. In this case, parameter $k$ serves only for a better fit. 


\section{CONCLUSION}

In this paper, we develop a term structure of interest rate convergence model within the no-arbitrage pricing framework. The model describes the convergence of EMU candidate countries' interest rates to the euro area interest rates. We consider both fixed and random EMU entry dates in the model setup.

Compared with other models developed so far in this field $(3 ; 13)$, the model specification developed in this paper ensures convergence of domestic short-term interest rates with euro ones by the entry date. It is achieved by assuming that the factor, the interest rate spread, follows the Brownian bridge process. Such an assumption avoids arbitrage opportunity in the model at the time of entering the EMU. The derived formulas lead to a more correct evaluation of prices of interest rate instruments and hence a more accurate extraction of market expectations from these prices.

We also develop an econometric counterpart of the theoretical model. The paper provides a framework of the econometric estimation for the model using the extended Kalman filter.

Empirical results show plausible parameter values. We compare the standard deviation of measurement errors for the proposed model and for J. Lund's version of the Vasicek model. The standard deviation of measurement errors in our model is smaller than in rival ones for Belgium, France, Italy and Spain; it is the same for the Netherlands, and slightly worse for Finland. For the Netherlands, the spread at short maturities did not converge to zero but only fluctuated around it over the considered sample, implying that the Brownian bridge process is not a completely correct specification for a short-term spread. For Finland, the observed term structure of yield spreads is diverging, thus an additional factor is needed to describe it correctly. In addition, our model contains a smaller number of parameters than the rival one (4 against 5).

The introduced model can be applied to develop an interest rate term structure model not only for a country planning to join the euro area but for any country planning to join any currency area. For example, the model could also be applied to Southeast Asian countries that negotiate a possibility to create their own currency area. 


\section{APPENDICES}

\section{Derivation of Discrete-Time State-Space Model Representation}

Let us assume that $n$ interest rates with maturities $\tau_{1}, \tau_{2}, \ldots, \tau_{n}$ exist in the market. The corresponding spreads with respect to euro rates are $\tilde{S}\left(\tau_{1}\right), \tilde{S}\left(\tau_{2}\right), \ldots, \tilde{S}\left(\tau_{n}\right)$. In such a case, taking into account equation [17], the model developed above can be rewritten as

$d \delta=-\frac{\delta}{T^{*}-t} d t+\sigma_{\delta} d w_{\delta}$

$\tilde{S}\left(t, \tau_{i}\right)=S\left(t, \delta, \psi, \tau_{i}\right)+\eta_{i}(t), i=1,2, \ldots, n$

where $S\left(t, \delta, \psi, \tau_{i}\right)=-\frac{\log F\left(t, \delta, \psi, \tau_{i}\right)}{\tau_{i}}$ is a theoretical spread from equation [34] ( $S$ depends on $\delta$, since it follows from equation [19] that $D$ depends on $\delta$ ), $\eta_{i} \sim N\left(0, \sigma_{\varepsilon}^{2} I\right)$ is the measurement error, $\psi$ is the vector of model parameters, and $\psi$ $=\left(\theta, \sigma_{\eta}, \sigma_{\delta}, \lambda_{1}\right)$.

Let us define the vectors

$$
\begin{aligned}
& \bar{S}(t, \delta, \psi)=\left[S\left(t, \delta, \psi, \tau_{1}\right), S\left(t, \delta, \psi, \tau_{2}\right), \ldots, S\left(t, \delta, \psi, \tau_{n}\right)\right], \\
& \overline{\widetilde{S}}(t)=\left[\tilde{S}\left(t, \tau_{1}\right), \tilde{S}\left(t, \tau_{2}\right), \ldots, \tilde{S}\left(t, \tau_{n}\right)\right]
\end{aligned}
$$

and

$\bar{\eta}=\left\lfloor\eta_{1}, \eta_{2}, \ldots, \eta_{n}\right\rfloor$.

The system of equations [37] and [38] determines a state-space system where equation [37] is a transition equation and equation [38] is a signal or measurement equation.(8; 9)

An exception of the problem is also random distribution of $T^{*}$ in equation [37]. Following the conventional approach of the stochastic differential equation theory (15), we define the solution of equation [37] as a function $\delta(t)$ which satisfies the following integral equation:

$$
\delta(t)=\delta\left(t_{0}\right)+\int_{\widetilde{T}}^{\infty}\left(\int_{t_{0}}^{t}-\frac{\delta(s)}{T^{*}-s} d s\right) \theta e^{-\theta\left(T^{*}-\widetilde{T}\right)} d T^{*}+\int_{t_{0}}^{t} \sigma d w(s) .
$$

A change in the order of integration in the first integrals gives 


$$
\begin{aligned}
& \delta(t)=\delta\left(t_{0}\right)+\int_{t_{0}}^{t} d s \int_{\widetilde{T}}^{\infty}\left(-\frac{\delta(s)}{T^{*}-s} \theta e^{-\theta\left(T^{*}-\tilde{T}\right)} d T^{*}\right)+\int_{t_{0}}^{t} \sigma d w(s)= \\
& =\delta\left(t_{0}\right)+\int_{t_{0}}^{t}-\theta e^{\theta(\tilde{T}-s)} E i(\theta(\tilde{T}-s)) \delta(s) d s+\int_{t_{0}}^{t} \sigma d w(s)
\end{aligned}
$$

where $\operatorname{Ei}(x)=\int_{1}^{\infty} \frac{\exp (-x t)}{t} d t$ is a special function known as exponential integral.(1)

The last expression is equivalent to the following stochastic differential equation:

$$
d \delta(t)=-\theta e^{\theta(\tilde{T}-t)} E i(\theta(\tilde{T}-t)) \delta(t)+\sigma d w(t)=B(t) \delta(t)+\sigma d w(t)
$$

Since the observations are discretely sampled, in order to produce econometric estimation, we need to transform the continuous-time state-space system of equations [37] and [38] into a discrete-time form. For this purpose, we consider an expression $d\left(X^{-1}\left(t, t_{0}\right) \delta(t)\right)$ where $X\left(t, t_{0}\right)$ is a fundamental solution of the following ordinary homogeneous differential equation:

$d \mathrm{X}\left(t, t_{0}\right)=-\theta e^{\theta(\tilde{T}-t)} E i(\theta(\tilde{T}-t)) \mathrm{X}\left(t, t_{0}\right) d t=B(t) \mathrm{X}\left(t, t_{0}\right) d t$

with initial condition $X\left(t_{0}, t_{0}\right)=1$

From equation [39] we can obtain

$$
\begin{aligned}
& d\left(X^{-1}\left(t, t_{0}\right) \delta(t)\right)=-X^{-2}\left(t, t_{0}\right) B(t) X\left(t, t_{0}\right) \delta(t) d t+X^{-1}\left(t, t_{0}\right) d \delta(t)=\{[39]\}= \\
& =-X^{-1}\left(t, t_{0}\right) B(t) X\left(t, t_{0}\right) \delta(t) d t+X^{-1}\left(t, t_{0}\right) B(t) \delta(t) d t+X^{-1}\left(t, t_{0}\right) \sigma d w(t)= \\
& =X^{-1}\left(t, t_{0}\right) \sigma d w(t)
\end{aligned}
$$

Integrating equation [42] from $t_{0}$ to $t$ and taking into account equation [41] we obtain

$$
\mathrm{X}^{-1}\left(t, t_{0}\right) \delta(t)-\delta\left(t_{0}\right)=\int_{t_{0}}^{t} \mathrm{X}^{-1}\left(s, t_{0}\right) \sigma d w(s)
$$

or

$$
\delta(t)=\mathrm{X}\left(t, t_{0}\right) \delta\left(t_{0}\right)+\int_{t_{0}}^{t} \mathrm{X}\left(t, t_{0}\right) \mathrm{X}^{-1}\left(s, t_{0}\right) \sigma d w(s)
$$

Thus, in order to obtain a discrete-time version of equation [39], we need to find function $X\left(t, t_{0}\right)$. For this purpose, equation [40] can be rewritten as

$$
\frac{d X\left(t, t_{0}\right)}{X\left(t, t_{0}\right)}=-\theta e^{\theta(\tilde{T}-t)} E i(\theta(\tilde{T}-t)) d t
$$

Integration of equation [45] from $t_{0}$ to $t$, taking into account equation [41], using the definition of function $E i$, and changing the order of integration result in 


$$
\begin{aligned}
& \ln X\left(t, t_{0}\right)=\int_{t_{0}}^{t}-\theta e^{\theta(\tilde{T}-s)} E i(\theta(\tilde{T}-s)) d s=\int_{t_{0}}^{t}-\theta e^{\theta(\tilde{T}-s)}\left[\int_{1}^{\infty} \frac{e^{-\theta(\tilde{T}-s) u}}{u} d u\right] d s= \\
& =\int_{t_{0}}^{t}\left[\int_{1}^{\infty}-\theta e^{\theta(\tilde{T}-s)} \frac{e^{-\theta(\tilde{T}-s) u}}{u} d u\right] d s=\int_{t_{0}}^{t}\left[\int_{1}^{\infty}-\theta \frac{e^{\theta(\tilde{T}-s)-\theta(\tilde{T}-s) u}}{u} d u\right] d s=\int_{t_{0}}^{t}\left[\int_{1}^{\infty}-\theta \frac{e^{\theta(\tilde{T}-s)(1-u)}}{u} d u\right] d s= \\
& =\int_{1}^{\infty}-\theta\left[\int_{t_{0}}^{t} e^{\theta(\tilde{T}-s)(1-u)} d s\right] \frac{1}{u} d u=\int_{1}^{\infty}-\theta\left\{-\frac{1}{\theta(1-u)}\left[e^{\theta(1-u)(\tilde{T}-t)}-e^{\theta(1-u)\left(\tilde{T}-t_{0}\right)}\right]\right\} \frac{1}{u} d u= \\
& =\int_{1}^{\infty}\left\{\frac{e^{\theta(1-u)(\tilde{T}-t)}-e^{\theta(1-u)\left(\tilde{T}-t_{0}\right)}}{u}+\frac{e^{\theta(1-u)(\tilde{T}-t)}-e^{\theta(1-u)\left(\tilde{T}-t_{0}\right)}}{(1-u)}\right\} d u= \\
& =\int_{1}^{\infty}\left\{\frac{e^{\theta(1-u)(\tilde{T}-t)}}{u}-\frac{e^{\theta(1-u)\left(\tilde{T}-t_{0}\right)}}{u}+\frac{e^{\theta(1-u)(\tilde{T}-t)}-e^{\theta(1-u)\left(\tilde{T}-t_{0}\right)}}{(1-u)}\right\} d u=I_{1}-I_{2}+I_{3}
\end{aligned}
$$

where the first integral is

$$
I_{1}=\int_{1}^{\infty} \frac{e^{\theta(1-u)(\tilde{T}-t)}}{u} d u=\int_{1}^{\infty} \frac{e^{\theta(\tilde{T}-t)} e^{-\theta(\tilde{T}-t) u}}{u} d u=e^{\theta(\tilde{T}-t)} E i[\theta(\tilde{T}-t)]
$$

The second integral is computed in the same way as

$$
I_{2}=e^{\theta\left(\tilde{T}-t_{0}\right)} E i\left[\theta\left(\tilde{T}-t_{0}\right)\right]
$$

For the third integral we have

$$
\begin{aligned}
& I_{3}=\int_{1}^{\infty} \frac{e^{\theta(1-u)(\tilde{T}-t)}-e^{\theta(1-u)\left(\tilde{T}-t_{0}\right)}}{1-u} d u=\left\{u u^{\prime}=u-1\right\}=\int_{0}^{\infty} \frac{e^{-\theta u(\tilde{T}-t)}-e^{-\theta u\left(\tilde{T}-t_{0}\right)}}{u^{\prime}} d u^{\prime}= \\
& =\int_{0}^{\infty} \frac{e^{-\theta u\left(\tilde{T}-t_{0}\right)}-e^{-\theta u(\widetilde{T}-t)}}{u^{\prime}} d u^{\prime}=\ln \frac{\theta(\tilde{T}-t)}{\theta\left(\tilde{T}-t_{0}\right)}=\ln \frac{(\widetilde{T}-t)}{\left(\widetilde{T}-t_{0}\right)} .
\end{aligned}
$$

From equations [46]-[49] it follows that

$$
\ln X\left(\mathrm{t}, \mathrm{t}_{0}\right)=e^{\theta(\tilde{T}-t)} E i[\theta(\tilde{T}-t)]-e^{\theta\left(\tilde{T}-t_{0}\right)} E i\left[\theta\left(\tilde{T}-t_{0}\right)\right]+\ln \frac{\tilde{T}-t}{\widetilde{T}-t_{0}}
$$

or taking the exponential of both sides yields

$$
X\left(t_{0}, t\right)=\frac{\tilde{T}-t}{\widetilde{T}-t_{0}} \exp \left\{e^{\theta(\tilde{T}-t)} E i[\theta(\tilde{T}-t)]-e^{\theta\left(\tilde{T}-t_{0}\right)} E i\left[\theta\left(\tilde{T}-t_{0}\right)\right]\right\}
$$

Assuming that $t_{\mathrm{i}}$ are known discrete-time moments, $i=1,2, \ldots, \mathrm{N}$, and the time interval between two consecutive time moments is given by $\Delta=t_{i}-t_{i-1}$, it follows from equation [50] that 


$$
\begin{aligned}
& X\left(t_{i}, t_{i-1}\right)=\frac{\tilde{T}-t_{i}}{\widetilde{T}-t_{i-1}} \exp \left\{e^{\theta\left(\tilde{T}-t_{i}\right)} E i\left[\theta\left(\tilde{T}-t_{i}\right)\right]-e^{\theta\left(\tilde{T}-t_{i-1}\right)} E i\left[\theta\left(\tilde{T}-t_{i-1}\right)\right]\right\}= \\
& =\frac{\tilde{T}-t_{i-1}-\Delta}{\widetilde{T}-t_{i-1}} \exp \left\{e^{\theta\left(\tilde{T}-t_{i-1}-\Delta\right)} E i\left[\theta\left(\tilde{T}-t_{i-1}-\Delta\right)\right]-e^{\theta\left(\tilde{T}-t_{i-1}\right)} E i\left[\theta\left(\tilde{T}-t_{i-1}\right)\right]\right\}= \\
& =\left(1-\frac{\Delta}{\widetilde{T}-t_{i-1}}\right) \exp \left\{e^{\theta\left(\tilde{T}-t_{i-1}\right)}\left[e^{-\theta \Delta} E i\left[\theta\left(\tilde{T}-t_{i-1}-\Delta\right)\right]-E i\left[\theta\left(\tilde{T}-t_{i-1}\right)\right]\right\}\right.
\end{aligned}
$$

Thus, from equations [44] and [51] we have obtained a recursive dependence of $\delta(t)$ on its previous value

$$
\delta\left(t_{i}\right)=\mathrm{X}\left(t_{i}, t_{i-1}\right) \delta\left(t_{i-1}\right)+\varepsilon\left(t_{i}\right)
$$

where

$$
\begin{aligned}
& \varepsilon\left(t_{i}\right)=\int_{t_{i-1}}^{t_{i}} X\left(t_{i}, t_{i-1}\right) X^{-1}\left(s, t_{i-1}\right) \sigma d w(s)= \\
& =\int_{t_{i-1}}^{t_{i}} \frac{\tilde{T}-t_{i}}{\widetilde{T}-s} \exp \left\{\begin{array}{l}
\left.e^{\theta\left(\widetilde{T}-t_{i}\right)} E i\left[\theta\left(\tilde{T}-t_{i}\right)\right]-e^{\theta\left(\tilde{T}-t_{i-1}\right)} E i\left[\theta\left(\tilde{T}-t_{i-1}\right)\right]-e^{\theta(\tilde{T}-s)} E i[\theta(\tilde{T}-s)]+\right\} \sigma d w(s)= \\
+e^{\theta\left(\widetilde{T}-t_{i-1}\right)} E i\left[\theta\left(\tilde{T}-t_{i-1}\right)\right]
\end{array}\right] \\
& =\int_{t_{i-1}}^{t_{i}} \frac{\tilde{T}-t_{i-1}-\Delta}{\widetilde{T}-s} \exp \left\{e^{\theta\left(\tilde{T}-t_{i-1}-\Delta\right)} E i\left[\theta\left(\tilde{T}-t_{i-1}-\Delta\right)\right]-e^{\theta(\tilde{T}-s)} E i[\theta(\tilde{T}-s)]\right\} \sigma d w(s) .
\end{aligned}
$$

The stochastic integral $\varepsilon\left(t_{i}\right)$ has normal distribution with zero conditional expectation $E\left(\varepsilon\left(t_{i}\right) \mid F_{t_{i-1}}\right)=0$, where $F_{t_{i-1}}$ is information available at time moment $t_{i-1}$. Conditional variance of $\varepsilon\left(t_{i}\right)$ follows from the properties of stochastic integral.(14; 15)

$$
\begin{aligned}
& \Gamma_{t_{i}}=\operatorname{Var}\left(\varepsilon\left(t_{i}\right) \mid F_{t_{i-1}}\right)=E\left(\varepsilon^{2}\left(t_{i}\right) \mid F_{t_{i-1}}\right)= \\
& =E\left(\left[\int_{t_{i-1}}^{t_{i}} \frac{\tilde{T}-t_{i-1}-\Delta}{\widetilde{T}-s} \exp \left\{e^{\theta\left(\tilde{T}-t_{i-1}-\Delta\right)} E i\left[\theta\left(\tilde{T}-t_{i-1}-\Delta\right)\right]-e^{\theta(\tilde{T}-s)} E i[\theta(\tilde{T}-s)]\right\} \sigma d w(s)\right]^{2} \mid F_{t_{i-1}}\right)= \\
& =\left[\left(\tilde{T}-t_{i-1}-\Delta\right) \sigma\right]^{2} \int_{t_{i-1}}^{t_{i}} \frac{1}{(\tilde{T}-s)^{2}} \exp \left\{2\left\{e^{\theta\left(\tilde{T}-t_{i-1}-\Delta\right)} E i\left[\theta\left(\tilde{T}-t_{i-1}-\Delta\right)\right]-e^{\theta(\tilde{T}-s)} E i[\theta(\tilde{T}-s)]\right\}\right) d s .
\end{aligned}
$$

Therefore, the system of equations [37] and [38] can be rewritten in a discrete-time state space representation as

$$
\delta\left(t_{i}\right)=\mathrm{X}\left(t_{i}, t_{i-1}\right) \delta\left(t_{i-1}\right)+\varepsilon\left(t_{i}\right)
$$


$\overline{\widetilde{S}}\left(t_{i}\right)=\bar{S}\left(t_{i}, \delta\left(t_{i}\right), \psi\right)+\bar{\eta}\left(t_{i}\right)$

where $X\left(t_{i}, t_{i-1}\right)$ is determined by equation [51] and $\bar{S}\left(t_{i}, \delta\left(t_{i}\right), \psi\right)$ by equation [34].

\section{Extended Kalman Filter Setup}

The measurement equation [53] is nonlinear with respect to state variable $\delta\left(t_{i}\right)$, hence, we need to use the extended Kalman filter.(9) In contrast to Lund's approach, we use the extended Kalman filter but not the iterative extended Kalman filter. This enables us to essentially speed up the filtering algorithm and, consequently, maximisation of the likelihood function.

To obtain the extended Kalman filter, we shall linearise equation [53] at point $\delta\left(t_{i} \mid t_{i-1}\right)$, where $\delta\left(t_{i} \mid t_{i-1}\right)=X\left(t_{i}, t_{i-1}\right) \delta\left(t_{i-1} \mid t_{i-1}\right)$ is a one-step-ahead state prediction at time moment $t_{i-1}$

$\bar{S}\left(t_{i}, \delta, \psi\right) \approx \bar{S}\left(t_{i}, \delta\left(t_{i} \mid t_{i-1}\right), \psi\right)+\frac{\partial \bar{S}}{\partial \delta}\left(t_{i}, \delta\left(t_{i} \mid t_{i-1}\right), \psi\right) \cdot\left(\delta-\delta\left(t_{i} \mid t_{i-1}\right)\right)$

The components of derivative vector $\frac{\partial S\left(t_{i}, \delta, \psi\right)}{\partial \delta}$ can be derived from equations [33], [34] and [19]:

$$
\frac{\partial \bar{S}\left(t_{i}, \delta, \psi, \tau_{i}\right)}{\partial \delta}=\left\{\begin{array}{l}
\frac{\theta \int_{T}^{\infty} D\left(t, T^{*}, T\right)\left(-B\left(t, T^{*}, T\right)\right) e^{-\theta\left(T^{*}-\tilde{T}\right)} d T^{*}}{F\left(t_{i}, \delta, \psi\right) \tau_{i}}, \tau_{i} \leq \tilde{T}-t_{i}, \\
\frac{J_{1}+J_{2}}{F\left(t_{i}, \delta, \psi\right) \tau_{i}}, \tau_{i} \geq \tilde{T}-t_{i}
\end{array}\right.
$$

where $J_{1}=\theta \int_{\widetilde{T}}^{T} D\left(t, T^{*}, T^{*}\right)\left(-B\left(t, T^{*}, T^{*}\right)\right) e^{-\theta\left(T^{*}-T\right)} d T^{*}$,

$J_{2}=\theta \int_{T}^{\infty} D\left(t, T^{*}, T\right)\left(-B\left(t, T^{*}, T\right)\right) e^{-\theta\left(T^{*}-T\right)} d T^{*}$

and $F\left(t_{i}, \delta, \psi\right)$ is given by equation [33].

Now, let us define the innovation vector

$$
\bar{\eta}\left(t_{i}\right)=\tilde{S}(t)-\bar{S}\left(t_{i}, \delta\left(t_{i} \mid t_{i-1}\right), \psi\right)
$$

The variance of prediction of observables is

$$
F_{t_{i}}=\frac{\partial \tilde{S}\left(t_{i}, \delta\left(t_{i} \mid t_{i-1}\right), \psi\right)}{\partial \delta} \sum_{t_{i} \mid t_{i-1}} \frac{\partial \tilde{S}\left(t_{i}, \delta\left(t_{i} \mid t_{i-1}\right), \psi\right)^{\prime}}{\partial \delta}+H_{t_{i}}
$$


where $\sum_{t_{i} \mid t_{i-1}}$ is the prediction variance of factor $\delta$ at time moment $t_{i-1}$ :

$\sum_{t_{i} \mid t_{i-1}}=X\left(t_{i}, t_{i-1}\right) \sum_{t_{i-1} \mid t_{i-1}} X\left(t_{i}, t_{i-1}\right)^{\prime}+\Gamma_{t_{i}}$

$H_{t_{i}}$ is the covariance matrix of vector $\eta\left(t_{i}\right), H_{t_{i}}=\sigma_{\eta}^{2} I$, where $I$ is a unit matrix.

Using information at moment $t_{i}$, the state updating equation is

$\delta\left(t_{i} \mid t_{i}\right)=\delta\left(t_{i} \mid t_{i-1}\right)+\sum_{t_{i} \mid t_{i-1}} \cdot \frac{\partial \widetilde{S}\left(t_{i}, \delta\left(t_{i} \mid t_{i-1}\right), \psi\right)}{\partial \delta} F_{t_{i}}^{-1} \eta\left(t_{i}\right)$

whereas the variance of this estimation is given by

$\sum_{t_{i} \mid t_{i}}=\left(\sum_{t_{i} \mid t_{i-1}}^{-1}+\frac{\partial \widetilde{S}^{\prime}\left(t_{i}, \delta\left(t_{i} \mid t_{i-1}\right), \psi\right)}{\partial \delta} H_{t_{i}}^{-1} \frac{\partial \widetilde{S}\left(t_{i}, \delta\left(t_{i} \mid t_{i-1}\right), \psi\right)}{\partial \delta}\right)^{-1}$

Therefore, the recursive estimation technique may be used in the same way as in the standard Kalman filter. Choosing any initial values $\delta_{0}$ and $\sum_{0}$ and using formulas [54]-[59], we can recursively compute innovations $\eta\left(t_{i}\right)$ and their covariance matrixes $F_{t_{i}}$.

Now, let us define the log-likelihood function

$L=\sum_{i=1}^{N}-\frac{1}{2}\left(\log \left|F_{t_{i}}\right|+\eta^{\prime}\left(t_{i}\right) F_{t_{i}}^{-1} \eta\left(t_{i}\right)\right)$

and, using some numerical method, calculate the parameter vector $\psi$ which maximises the likelihood function. The most complicated task in this procedure is computing function $S$ and its derivatives at each step, since $S$ is defined by log from improper integrals in equation [33], which are rather nonlinear functions. The use of numerical methods is vitally required. 


\section{BIBLIOGRAPHY}

1. ABRAMOWITZ, Milton, STEGUN, Irene A. Handbook of Mathematical Functions. Dover Publications : New York, 1965.

2. BATES, David S. Financial Markets' Assessment of EMU. NBER Working Paper, No. 6874, January 1999.

3. CORZO, Santamaria Teresa, SCHWARTZ, Eduardo S. Convergence within the EU: Evidence from Interest Rates. Economic Notes, vol. 29, No. 2, July 2000, pp. 243-266.

4. De GRAUWE, Paul. Forward Interest Rates as Predictors of EMU. CEPR Discussion Paper, No. 1395, May 1996.

5. DUFFIE, Darrell. Dynamic Asset Pricing Theory. Princeton University Press : Princeton, 2001.

6. DUFFIE, Darrell, SINGLETON, Kenneth J. Credit Risk. Princeton University Press : Princeton, 2003.

7. FAVERO, Carlo Ambrogio, GIAVAZZI, Francesco, IACONE, Fabrizio, TABELLINI, Guido. Extracting Information from Asset Prices: the Methodology of EMU Calculators. CEPR Discussion Paper, No. 1676, July 1997.

8. HAMILTON, James D. Time Series Analysis. Princeton University Press : Princeton, 1994.

9. HARVEY, Andrew C. Forecasting, Structural Time Series Models and the Kalman Filter. Cambridge University Press : New York, 1989.

10. KARATZAS, Ioannis, SHREVE, Steven E. Brownian Motion and Stochastic Calculus. Springer-Verlag : Berlin, 1991.

11. LANDO, David. On Cox Processes and Credit Risky Securities. Review of Derivatives Research, vol. 2, No. 2-3, December 1998, pp. 99-120.

12. LUND, Jesper. Five Essays in Financial Econometrics and the Term Structure of Interest Rates, Ph. D. Dissertation. Department of Finance, the Aarhus School of Business, July 1997 [cited on 24 October 2008]. Available:

http://www.jesperlund.com/thesis/.

13. LUND, Jesper. A Model for Studying the Effect of EMU on European Yield Curves. European Finance Review, vol. 2, No. 3, 1999, pp. 321-363.

14. PROTTER, Philip E. Stochastic Integration and Differential Equations. Springer-Verlag : Berlin, 2005.

15. REVUZ, Daniel, YOR, Marc. Continuous Martingales and Brownian Motion, Springer-Verlag : Berlin, 1999.

16. VASICEK, Oldrich. An Equilibrium Characterization of the Term Structure. Journal of Financial Economics, vol. 5, issue 2, November 1977, pp. 177-188. 